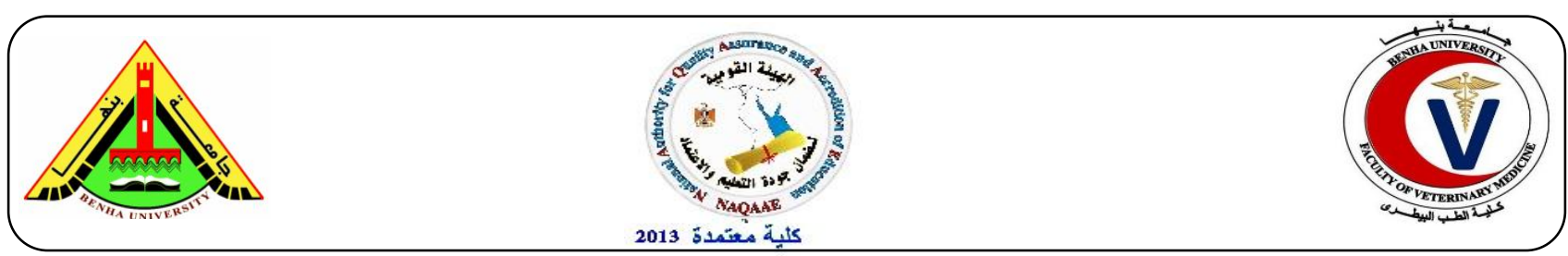

\title{
Effect of the day period on the behavior of adult breeding ostriches (Struthio camelus)
}

\author{
Ramadan, M. M., Ahmed, E. A., El-Laithy S. M., Heba, A. A
}

Department of Veterinary Hygiene and Management, Faculty of Veterinary Medicine, Benha University

\section{A B S T R A C T}

The objective of this work was to evaluate the effect of period of the day on the behavior of adult breeding ostriches (Struthio camelus) in a farming environment. A twenty -one mature African black neck breed ostriches ( 7 males and14 females) were used .The birds were divided into 7 groups(1male:2 females)per group. The observations were carried out at three different periods; morning (8:00 a.m. to 9:00 a.m), at noon (11:00 a.m. to 12:00 p.m) and at afternoon (4:00 p.m. to 5:00 p.m).

Feeding, drinking, walking, running, thermoregulation, body care and aggressive behaviors were recorded following through number of individuals observed to be in the act of pattern at 30seconds interval during the observation session ( 5 minutes). The order of observation was randomized for each group .By this system of rotation with in the periods of days we have a sheet of three daily periods as reprehensive to the week. When the periods noon/afternoon were compared, there was significant differences in walking, running, drinking water, eating ration, litophagia, dancing, sand bathing. It was observed that the behavior of ostriches differ according to day period.

Keywords: Behavior, day period, ostriches (Struthio camelus).

\section{INTRODUCTION}

The ostrich (Struthio camelus) is a flightless bird belonging to the ratite family and known as the largest living bird. Ostrich is native to semi-arid and desert areas of Africa, they have been raised intensively in South Africa for more than 100years ostrich are reared commercially mainly to produce usable products, including meat, hides, feathers, and eggs (Kreibich and Sommer, 1995).The ostrich is a good farm bird as it give 1.4-1.8 $\mathrm{kg}$ of feathers, 34-41 kg of low-fat red meat, and $1.1-1.3 \mathrm{~m}^{2}$ of leather. They are the extant bird with two toes on each foot (Schaller et al., 2011). The adult male bird has a grey colored neck with black and white wing primaries and tail feathers. The female has white to light grey wing primaries and tail feathers and body have color pattern dull brown to grey. Ostriches spent most of their time eating standing and walking and they frequently preen feathers with their beaks (grooming behavior) and they do this while walking, sitting, standing, or even in rainy days (Menon et al., 2014). The behavior of ostriches differ according to the age and day period (Amado et al., 2011).Higher 
consumption of food was noticed during the morning when the food was supplied (Deeming 1998) while Souza (2004) noticed that ostriches in captivity and in hot weather conditions drink water at dawn and at dusk, McKeegan \& Deeming (1997) reported that the birds were moving more in the early hours of the day and at the end of the afternoon. Thermoregulations by ostriches were accompanied with flapping of wings, openmouth breathes or yawning in the afternoon as a means of dissipating heat from the body (Mushi et al., 2008).

Recent interest in ostrich farming has led to increase the need for information about this bird and how to manage it in a commercial environment.

The object of this study was to evaluate the effect of period of the day on the behavior of adult breeding ostriches (Struthio camelus) during different periods of the day in a farming environment.

\section{Materials and methods}

This study was carried out in a private Ostrich Farm located in $\mathrm{El}$-Obour kalyubia province, Egypt.

\subsection{The birds:}

A total number of 21 birds of mature African black neck breed ostriches (7 males and 14 females) were used. They housed in 7 enclosures with sex ratio 1:2 .The age was about 5 years for males and4 years for females. Ostriches were maintained in enclosures (paddocks) on the sand floor surrounded by wire fencing. There was nearly a600 $\mathrm{m}^{2}$ per3 birds in the enclosures (intensive rearing system). The experimental period was extended for 8 weeks from August to September 2017. Drinking water was available at all time. All birds were subjected to the same managerial and hygienic conditions. All breeding birds were daily fed 2 Kilograms per bird (divided on two times per day) formulated ostrich breeder ration containing $20 \%$ crude protein according to Scheideler et al. (1997) and shown in table (1) supplied throughout the breeding season.

\subsection{Behavioral observations:-}

The behavioral observation was performed according to the recommendation of( Paul and Patrick,2007).The observations were carried out at three different periods; morning started from(8;00-9.00), at noon from(11;00-12;00) and at afternoon from(4.;00-5;00) For three days weekly to obtain three daily observations period for each group. Behavioral Patterns were recorded by using scan sampling method and point sampling recording rule.So each period of observation spent 30 minutes for recording the different behavioral activities. Feeding,drinking,walking,running,thermoregu lation,body care and aggressive behavior were recorded as follow the number of individuals observed to be in the act of pattern at 30seconds interval during the observation session (5 minutes). The order of observation was randomized for each group .By this system of rotation with in the periods of days we have a sheet of three daily periods as representative to the week.

\subsection{Statistical analysis:}

Data collected were statistically analyzed by using Mann Whitney test that compare the behavior of birds among periods of the day. Kruskal-Wallis test was used for differences in the expression of individual behaviors. 
Table 1: The composition and nutritive value of the basal breeder diet

\begin{tabular}{lc}
\hline \multicolumn{1}{c}{ Ingredients } & Percentage $\%$ \\
\hline Yellow corn & 24 \\
Soy bean meal (44\%) & 20 \\
Dried alfalfa & 33 \\
Wheat bran & 15 \\
Dicalcium phosphate & 3 \\
Calcium carbonate & 3 \\
Salt & 0.5 \\
Vit and mineral mix & 0.6 \\
Methionin & 0.2 \\
Lysine & 0.2 \\
Choline & 0.1 \\
Zinc bacitracin & 0.2 \\
Antioxidant & 0.2 \\
Total & 100 \\
Calculated analysis & \\
Crude protein & $2500(\mathrm{~K} \mathrm{cal} / \mathrm{kg})$ \\
ME(K cal/kg) & $14 \%$ \\
Fiber & $3 \%$ \\
Fat & 0.38 \\
Methionine & 1.00 \\
Lysine & 2.4 \\
Calcium & 0.7 \\
Phosphorus & $20 \%$ \\
& \\
\hline & \\
\hline
\end{tabular}

Formulation according to Scheideler et al. (1997) and calculated according to NRC(1994)

Table 2: Behavioral patterns recorded in this study and the related description was as follows.

\begin{tabular}{ll}
\hline Activity & Description of recorded activity \\
\hline Ingestion & Consuming the concentrate feed. \\
Feeding & Touching water surface with the beak with or without gulping \\
Drinking & action. \\
& consumption of stones.
\end{tabular}

Lithophagia

Grooming

Dust bathing

Rubbing the neck or any portion of body against the ground, 
Locomotion

Running

Walking

Standing

Socialization

Aggression

Threatening

shaking both wings either crouching or sitting.

Running sprints (with or without the wing extended) but not chasing other ostrich.

Walking with or without the wings extended.

Standing with the neck in S shape and feathers flattened or straight.

Attacking other ostrich (contact between bodies by kicking/pushing).

Standing tip-toed and making a hissing sound towards other ostrich.

Resting

Sitting

Crouching/sitting with or without the head raised.

Thermoregulation

Yawning

Opening mouth briefly and closing it.

\section{RESULTS}

Table e shows some behaviors of ostriches in relation to the period of the day

Table 3: Mean values $( \pm$ SD) of some behaviour of ostriches in relation to the period of the day.

Behavior

$$
\text { periods of the day }
$$

\begin{tabular}{lccc}
\hline & Morning & noon & afternoon \\
\hline Standing & $0.98 \pm 0.16^{\mathrm{a}}$ & $0.53 \pm 0.07^{\mathrm{b}}$ & $0.72 \pm 0.10^{\mathrm{ab}}$ \\
Walking & $4.22 \pm 0.14^{\mathrm{a}}$ & $3.07 \pm 0.14^{\mathrm{b}}$ & $4.33 \pm 0.16^{\mathrm{a}}$ \\
Running & $0.34 \pm 0.11 \mathrm{a}^{\mathrm{b}}$ & $0.18 \pm 0.05^{\mathrm{b}}$ & $0.45 \pm 0.07^{\mathrm{a}}$ \\
Drinking & $1.09 \pm 0.16^{\mathrm{ab}}$ & $0.79 \pm 0.07^{\mathrm{b}}$ & $1.15 \pm 0.12^{\mathrm{a}}$ \\
Feeding & $3.50 \pm 0.17^{\mathrm{a}}$ & $1.93 \pm 0.13^{\mathrm{b}}$ & $3.14 \pm 0.15^{\mathrm{a}}$ \\
Sand bathing & $0.00 \pm 0.00^{\mathrm{b}}$ & $0.04 \pm 0.01^{\mathrm{a}}$ & $0.30 \pm 0.05^{\mathrm{b}}$ \\
Aggression & $0.90 \pm 0.29^{\mathrm{a}}$ & $0.03 \pm 0.02^{\mathrm{b}}$ & $0.00 \pm 0.00^{\mathrm{b}}$ \\
Lithophagia & $2.27 \pm 0.34^{\mathrm{a}}$ & $1.56 \pm 0.16^{\mathrm{b}}$ & $2.19 \pm 0.24^{\mathrm{a}}$ \\
yawn & ---- & $0.550 \pm .08^{\mathrm{b}}$ & $0.738 \pm .13^{\mathrm{a}}$ \\
\hline
\end{tabular}

Average values in the same raw, with different letters significantly different $(\mathrm{P}<0.05)$ by KruskalWallis test.

\section{DISCUSSION}

Ingestive behavior includes all feeding and drinking behaviors.
From the obtained results it is clear that feeding behavior of ostrich is higher in $\mathrm{p} 1$ $(3.50 \pm 0.17 \mathrm{a})$ than $\mathrm{p} 2(1.93 \pm 0.13 \mathrm{~b})$ and 
p3(3.14 \pm 0.15a).There were significant difference $(\mathrm{p} \leq 0.05)$ in feeding behavior due to the period of the day as ostrich feeding behavior was more in $\mathrm{p} 1$ than $\mathrm{p} 2$ and $\mathrm{p} 3$, The differences may be due to lower environmental temperature, as well as the time when food is distributed. Higher temperatures from 11:00 a.m. to 3:00 p.m. may have led to a decrease in the food consumption to avoid heat enhancement due to the digestion process. The obtained results were in accordance with Deeming (1998) who found higher consumption of food during the morning when the food was supplied and also McKeegan\& Deeming (1997) was observed pairs of adult ostriches in captivity, reported a peak in the consumption of feed in the morning for both sexes.

Lithophagia is the consumption of stones. Small stones were consumed as a daily routine by all groups due to the conformation of the digestive system of birds and lack of structures for maceration of the food ingested. From the obtained results it is clear that Lithophagia of ostrich is higher in p1(2.27 \pm $0.34 \mathrm{a})$ than $\mathrm{p} 3(2.19 \pm 0.24 \mathrm{a})$ and $\mathrm{p} 2(1.56 \pm$ $0.16 \mathrm{~b})$. The result may be due to it coinciding with food distribution or food intake. Milton \& Dean (1995) cleared that ostriches need to consume stones for their digestive process and to separate the nutrients from the feed more completely.

From the obtained results it is clear that drinking behavior of ostrich is higher in $\mathrm{p} 3(1.15 \pm 0.12 \mathrm{a})$ than $\mathrm{p} 1(1.09 \pm 0.16 \mathrm{ab})$ and $\mathrm{p} 2(0.79 \pm 0.07 \mathrm{~b})$. The water consumption may be related to the time of food consumption or environmental dryness and high environmental temperatures. The obtained results in accordance with (Souza, 2004) who found that ostriches in captivity and in hot weather conditions drink water at dawn and at dusk. High temperatures of approximately $35^{\circ} \mathrm{C}$ from 11:00 to 3:00 p.m. during experimental period may have caused a decrease in bird activity during this period. The birds were observed drinking water and feeding with lower frequency in the middle of the day than to the other periods.

Locomotary behavior can be represented into walking and running. From the obtained results it is clear that walking behavior of ostrich is higher in p3(4.33 \pm $0.16 \mathrm{a})$ than $\mathrm{p} 2(3.07 \pm 0.14 \mathrm{~b})$ and $\mathrm{p} 1(4.22 \pm$ $0.14 \mathrm{a})$.There were significant difference $(p \leq 0.05)$ in locomotion behavior due to the period of the day as ostrich running behavior was more in $\mathrm{p} 3(0.45 \pm$ $0.07 \mathrm{a})$ than $\mathrm{p} 2(0.18 \pm 0.05 \mathrm{~b})$ and $\mathrm{p} 1(0.34 \pm$ $0.11 \mathrm{ab})$. The obtained results in accordance with Mushi et al., (2008) who reported that in general, all the age groups of ostriches spent about $60 \%$ of the afternoon either standing or walking. Walking was the most frequent locomotion behavior observed followed by running. The obtained results were in accordance with Berendsen (1995) who noticed that the ostriches at the farm in Germany spent most their time walking rather than running. According to Mushi et al., (2008) this behavior was gender-dependent with males spending more time in walking probably because they watching around predators while the females brood over the eggs sitting on the nests.

Resting behavior of ostriches (S. camelus) occurred when they stopped moving from doing any activities. The resting behaviors were highest in the morning followed by evening and afternoon. The difference in resting behavioral patterns between different observational periods was significantly difference $(\mathrm{p} \leq 0.05)$. There was none sleeping position observed during the observation period in which it suggested that the ostriches only tend to sleep during night time. This is due to the ostriches are diurnal animals where they are most active early and 
late in the day (Davies, 2003), but may be active on moonlight nights. This is supported by Degen et al., (1989) and Deeming (1998) who noticed that most ostriches sit during sunset and were inactive all night.

Comfort behaviors include sand bathing, care of plumage and other parts of body. During sand bathing, the ostrich would lie down in a dry sandy place. It would then push the neck into the sand using snake-like motions and shovel sand over the body as reported by (Muhsi et al., 2008). This activity was frequently occurred in the afternoon $(0.04$ \pm 0.01 a) followed by evening $(0.30 \pm 0.05 b)$ and morning $(0.00 \pm 0.00 \mathrm{~b})$. The obtained results were in accordance with Sambraus (1994b) who reported that the incidence of this ostrich behavior was very low in the morning and increased in the afternoon with peaks at sunset. This may be due to the dry conditions in the afternoon due to high temperature that had been a contributory factor to the highest frequency during this period. The difference in comfort behavioral patterns between different observational periods was significantly $(\mathrm{p} \leq 0.05)$. Birds were observed to perform sand bathing in groups as one bird may encourage the others to do and it is usually performed in the same location in the paddock.

The ostriches are slightly different from the other species of birds in which they do not have uropygial gland or formally known as the preen gland or the oil gland. The functional of the gland is to clean the feathers naturally. Based on the observations, grooming activity by ostriches were to remove foreign objects embedded at their feathers like leaves and dirt.

Regarding the aggressive behavior. The threat behavior occurred when the ostrich stand tall with tail erect, hissing, wings slightly open and feathers puffed up, especially around the neck. From the obtained results it is clear that aggressive behavior of ostrich is higher in $\mathrm{p} 1(0.90 \pm 0.29 \mathrm{a})$ than $\mathrm{p} 2(0.03 \pm 0.02 \mathrm{~b})$ and $\mathrm{p} 3(0.00 \pm 0.00 \mathrm{~b})$.

By the observations, aggressive behavior was cleared when the ostriches faced the disturbance like met the strangers and also when the keeper came to fed them. This was in agreement with Muhsi et al., (2008) which noticed that, aggressive behavior was demonstrated between hens and cocks and also towards human intruders. This behavior was demonstrated by the male ostriches only. The aggression behavior was prevalent in the morning in comparison to both afternoon and evening. The difference in aggression behavioral patterns between different observational periods was not significantly different $\quad(\mathrm{p} \geq 0.05) . \quad$ Thermoregulations accompanied with flapping of wings, openmouth breathes or yawning and were shown by ostriches in the afternoon as a means of dissipating heat from the body as reported by Mushi et al., (2008). From the obtained results it is clear that thermoregulations behavior of ostrich is higher in p3 $(0.738 \pm .13$ a) than $\mathrm{p} 2(0.550 \pm .08 \mathrm{~b})$ and not observed in p1.

This was because the high temperature in the afternoon that required the ostriches to dissipate more heat during this period. These results were in agreement with Muhsi et al., (2008). The difference in thermoregulation behavioral patterns between different observational periods was significantly difference $(\mathrm{p} \leq 0.05)$.

\section{Conclusions:}

On conclusion this study displayed ostrich behavior that changed during the day, includes and bathing this activity was frequently occurred in the afternoon $(0.04 \pm$ $0.01 \mathrm{a})$ followed by evening $(0.30 \pm 0.05 \mathrm{~b})$ and morning $(0.00 \pm 0.00 \mathrm{~b})$. Also yawning 
behavior of ostrich is higher in p3 $(0.738 \pm .13$ a) than $\mathrm{p} 2(0.550 \pm .08 \mathrm{~b})$ and not observed in p1. Moreover aggressive behavior of ostrich is higher in p1 $(0.90 \pm 0.29 \mathrm{a})$ than $\mathrm{p} 2(0.03 \pm$ $0.02 \mathrm{~b}$ )and p3 $(0.00 \pm 0.00 \mathrm{~b})$. More studies should be carried out to determine the real needs of this bird and to define the exact normal behavior under the ideal conditions.

\section{REFERENCES}

Amado MF, Xavier DB, Boere V, TorresPereira C, McManus $\mathrm{C}$ and Bernal FEM (2011). Behaviour of captive Ostrich chicks from 10 days to 5 months of age. Revista Brasileira de Zootecnia, 40(7): 16131618.

Berendsen, K.D. (1995). Behaviour. In: Kreibich, A., Sommer, M. (Eds.), Ostrich Farm Management. LandwirtschaftsVerlag,

Münster-Hiltrup, pp. 25-32.

Davies, S.J.J.F. (2003). "Birds I Tinamous and Ratites to Hoatzins". In Hutchins, Michael.Grzimek's Animal Life Encyclopedia8 (2 ed.). Farmington Hills, MI: Gale Group. pp. 99-101.ISBN 0-7876-5784-0.

Deeming DC (1998). A note on effects of gender and time of day on the winter time-activity budget of adult ostriches (Struthio camelus) in a farming environment. Appl Anim BehavSci 59: 363-371.

Degen, A.A., Kam, M. and Rosenstrauch, A. (1989). Time-activity budget of ostriches (Struthiocamelus) offered concentrate feed and maintained in outdoor pens. Applied Animal Behavioural Science, 22: 347-358.

Kreibich, A., and Sommer, M. (1995). Miscellaneous. In: kreibich, A., and Sommer, M. (eds.). Ostrich farm management, (Landwirtschaftsverg, Gmbh, Munster- Hiltrup, Germany), 166-169.

Kruskal-Wallis.Use of ranks in one -criterion variance analysis. Journal of the American statistical Association.

McKeegan DEF, Deeming DC (1997). Effects of gender and group size on the time-activity budgets of adult breeding ostriches (Struthio camelus) in a farming environment. Appl Anim Behav Sci 51: 159177.

Milton S and Dean R (1995).Gizzard stones and food selection by freerange ostrich implications for management. East Coast Producers Association January/February, 4-7.

Mushi EZ, Binta MG, Chabo RG and Galetshipe O (2008). Problems associated with artificial incubation and hatching of Ostrich (Struthio camelus) eggs in Botswana. Res. J. Poult. Scis. 2(2): 21 26.

Menon DG, Bennett DC and Cheng KM (2014). Understanding the Behavior of Domestic Emus: A Means to Improve Their Management and Welfare - Major Behaviors and Activity Time Budgets of Adult Emus. Journal of Animals, vol. 2014: 8 pages, Article ID 938327. DOI:10.1155/2014/938327.

National research council (1994). Nutrient requirement of poultary. 9 rev. ed. National academy press. Washington, D. C.

Paul and Patrick, (2007). Measuring behavior ,An introduction Guide. Third edition .Chapter5;p:48:60.

Souza JS, Criação de avestruz. Viçosa, MG: Aprenda Fácil. (2004) PhD Thesis, University of Wageningen. 
Sambraus, H.H. (1994). The circadian rhythm in the behavior of ostriches (Struthiocamelus) kept in pens. Berliner und MünchenerTierärztliche. Wochenschrift, 107: 339-341.SAMBRAUS, H.H. Comfort behavior of the African ostrich (Struthio camelus).

Schaller, N.U., D'Août, K., Villa, R., Herkner, B. and Aerts, P. (2011). Toe function and dynamic pressure distribution in ostrich locomotion. The Journal of Experimental Biology 214: 1123-1130.

Scheideler, S.E and Sell,J.L. (1997). Nutrition guidelines for ostriches and emus .IOWA state university, university extension. 